Psicologia \& Sociedade; 16 (1): 69-85; Número Especial 2004

\title{
O PESQUISADOR FRENTE À AVALIAÇÃO NA PÓS-GRADUAÇÃO: EM PAUTA NOVOS MODOS DE SUBJETIVAÇÃO
}

\author{
Margarete Axt \\ Universidade Federal do Rio Grande do Sul
}

RESUMO: Pensar o atual Modelo CAPES de Avaliação da Pós-Graduação (PG), no Brasil, traz à visibilidade reflexiva alguns componentes do mecanismo que acabou por produzir esse dispositivo de subjetivação do pesquisador, desde sua criação na década de setenta, passando pelos processos de globalização da economia e de expansão das telecomunicações até a criação da OMC na década de noventa, seguida de um acirramento das estratégias de competição e de individualização. Das linhas que nos chegam com efeitos diversos, configurando um complexo contexto da PG brasileira, trago, para discutir, três desdobramentos - indicadores de produtividade do pesquisador; indicadores de qualidade definidos pelos QUALIS das áreas; e a ressuscitada taxa de bancada do $\mathrm{CNPq}$-, tal como os consigo delinear neste momento, buscando dar-lhes um contorno de cena em curso, na perspectiva do pesquisador. Produzidas historicamente, essas cenas perspectivadas podem sugerir um processo crescente de estraçalhamento do pesquisador em diferentes níveis: (a) no interior do Programa, pela contínua exigência para atingir os índices de qualidade esperados; (b) na sua própria área de conhecimento, em especial quando atuante em dois Programas de PG, precisando atender a dois QUALIS; (c) no interior do grupo de pesquisa, pelas assimetrias que vão se formando nas relaçôes, em vista do tratamento diferenciado a bolsistas CNPq. Se a avaliação é condição necessária para o crescimento da excelência na Pesquisa e na formação PósGraduada, não é, contudo, condição suficiente: cabe criar condições de possibilidade na instância micropolítica para, com base em avaliações coletivas de conjunto, propor estratégias de intervenção que trabalhem no engendramento de novos agenciamentos, na contracorrente do pensamento homogêneo, individualizante e de competição excludente. Tais movimentos, ao adquirirem força de 
Axt, $M$.

"O pesquisador frente à avaliação na pós-graduação: em pauta novos modos

de subjetivação"

potência, podem provocar a emergência, na instância macropolítica, de modelos de avaliação mais contemporâneos, perspectivando questôes científico-políticas na dimensão do seu compromisso com uma ética-estética.

PALAVRAS-CHAVE: avaliação e gestão, ensino superior e pósgraduação e pesquisa, subjetivação e subjetividade.

\section{RESEARCHER FACING POST-GRADUATION EVALUATION: UNDER DISCUSSION, NEW WAYS OF SUBJECTIVATION}

ABSTRACT: Thinking the current CAPES model of PostGraduation evaluation, in Brazil, brings into a reflexive visibility some components of the mechanism that ended producing this subjectvation device of the researcher, since its creation in the seventies, through the process of globalization of the economy and expansion of telecommunications until the creation of the World Trade Organization in the nineties, followed by a stimulation of competition and individualization strategies. From the lines that come to us with several effects, configuring a complex context of Brazilian Post-Graduation, I bring three issues to be discussed indicators of the researcher's productivity; quality indicators defined by the QUALIS of their areas; and the ressuscitated fee for CNPq board-, as I am able to trace at this moment, trying to give them an outline of the scene in course, in the researcher's perspective. Historically produced, these scenes, in perspective, may suggest an increasing process of shattering to the researcher in different levels: (a) inside the Post-Graduation Program, by the continuous requirement to reach the expected quality rates; (b) in the researcher's own knowledge area, specially when working in two Post-Graduation Programs, needing to attend to two QUALIS; (c) inside research groups, by asymmetries that are formed in the relations due to differentiated treatment towards $\mathrm{CNPq}$ scholarship holders (National Council of Scientific and Technological Development). If evaluation is a necessary condition to increase research and Post- 
Psicologia \& Sociedade; 16 (1): 69-85; Número Especial 2004

Graduation education excellence, it is not, however, the only condition: it is needed to create conditions to possibilities in micropolitics instances to propose, based on collective evaluations, intervention strategies that work linking and producing new connections, in the countercurrent of the homogeneous, individualizing thinking and excluding competition. Such movements, when acquiring strength and power, may provoke the emergence, in macropolitic instance, of more contemporaries evaluation models, setting under perspective scienfific-politics issues in the dimension of its commitment with an ethic-aesthetic.

KEYWORDS: evaluation and management, college education and post-graduation and research, subjectivation and subjectivity.

\section{O TEMPO PARADOXO}

Frente a frente com o contexto do nosso Presente, enquanto pesquisadora vinculada à PÓS-GRADUAÇÃO (no Brasil), ocorreu-me lembrar das nossas imbricaçôes com Tempo, de como chegamos aonde chegamos... e mais uma vez me dei conta de que sempre que problematizamos uma determinada época, a nossa época, a História, o Futuro, deparamo-nos dramaticamente com o paradoxo do Tempo trazido à tona, talvez em uma primeira vez, por Santo Agostinho, ainda no século $\mathrm{V}$ e depois retomado e tão discutido por diferentes autores, entre os quais os que aqui tomo por referência, como Bergson, Deleuze e Boaventura Santos. ${ }^{1}$

A partir dessa referência inicial (e já atrelando-a ao nosso Presente), podemos nos perguntar um tanto retoricamente: $\mathrm{O}$ que é o Presente? Para logo então responder:

1) de um lado, pode-se pensar/dizer do Presente, que é pura duração, pura simultaneidade e, nesse sentido, um longo e duradouro Presente!

2) de outro lado, reafirmaríamos o Presente como sempre dividido, sempre um Não-lugar, ${ }^{2}$ pelo qual apenas transitamos, estando sempre de passagem, transpondo... - um pé cá (no

1 Bergson, 1990. Deleuze, 1988; 1999. Santos, 1999.

2 Aproveitando o conceito proposto por Augé, 1994. 
Axt, $M$.

"O pesquisador frente à avaliação na pós-graduação: em pauta novos modos

de subjetivação"

chão firme do passado) e um pé lá (no ar, ainda sem chão, no devir) -, simultaneamente instituindo território e abrindo à desterritorialização; sendo efeito de subjetivida de produzida e à espreita de processos de subjetivação em formação; sendo componente de agenciamentos constituídos, mas também de agenciamentos em vias de composição.

Confrontados com o paradoxo do Tempo, estamos perenemente em crise: sempre somos o que já trazemos das memórias, das marcas da História; porém sem sermos completamente, pois ao mesmo tempo estamos sempre em processo de ser, em devir. Estamos em crise, num Presente que se engendra por um emaranhado de linhas provenientes das histórias de um Passado, produzindo, sem parar e por obsessão, um Nó (problemático!), ${ }^{3}$ cujo deslindamento apenas virtualmente se projeta em expectativa, insinuando, sugerindo (e até antecipando) devires ainda não constituídos, ainda em processo, na dependência da passagem pelo Presente, do passo que se desenha no ar, do pé que busca chão firme para fazer território.

O Nó crítico, problemático, da Pós-Graduação (PG) no Brasil - esta considerada na perspectiva dos Modelos de Avaliação em voga -, traz à visibilidade reflexiva Linhas de um Passado Histórico, vetorializando um Futuro que, em que pese pensar-se o contrário, ainda não está dado, encontra-se sempre em processo...

Que linhas serão afirmadas e projetadas com o passo que se desenha no ar? Como trabalhar com as Linhas desse $N o ́$, puxando as que possam potencializar a vida, o fazer/pensar criativos, modos de pesquisar produtores de conhecimento relevante, voltados para o cuidado com uma estética do produzir no cotidiano acadêmico, comprometido eticamente com uma ecologia relacional-política de preservação da biodiversidade e das diferenças culturais? São questôes que cabem aos pesquisadores brasileiros responder, enquanto coletivo de enunciação! O que nos é possível, neste momento, é trazer algo da proveniência genealógica desse dispositivo de subjetivação do pesquisador e da formação em pesquisa, alguns dos processos atuais de produção dos modos de ser pesquisador, além de algumas poucas projeçôes virtuais decorrentes das reflexôes sobre os itens anteriores.

3 Deleuze, 1988. 


\section{ALGO DO CONTEXTO HISTÓRICO - PRODUÇÃO DO DISPOSITIVO DE SUBJETIVAÇÃO}

Procurando projetar um pouco o futuro, tracemos, antes, algumas das linhas que parecem estar contribuindo para os vetores que vêm sustentando nosso Presente, seguindo-as no sentido de sua proveniência; identificamos, então, dentre outras:

1) políticas de criação e de fomento da pós-graduação e de pesquisa ainda na década de setenta, no Brasil, abrindo espaço à formação pós-graduada e à pesquisa, bem como à organização do seu fomento;

2) a invenção e a consolidação, já na década de noventa, da globalização da economia, acompanhada (e subsidiada) pelo desenvolvimento espantoso das telecomunicaçôes, em particular a Internet, e por uma nova divisão internacional do trabalho, definindo dentre outras coisas, quem são os produtores de ciência e tecnologias e quem são os consumidores; ${ }^{5}$

3) a invenção e a consolidação da OMC (Organização Mundial do Comércio), ainda em 1995, bem como a investida da mesma no terreno da Educação, declarando-a sujeita às regras do comércio internacional, e colocando, em especial a Educação Superior, em risco no marco de uma economia de mercado, como conseqüência da resolução adotada em 2002. Esta resolução, em discussão em vários países dentre os quais o Brasil, inclui a Educação como serviço comercial regulado pelo Acordo Geral de Comércio e Serviços (GATS) ${ }^{6}$ - há, mesmo, quem diga que a $\mathrm{OMC}$ represente um supra governo econômico internacional acima dos governos nacionais e afetando-os nos planos executivo, legislativo e judicial, de modo que o conceito de soberania nacional já teria perdido, hoje, todo o seu significado; ${ }^{7}$

4 Em que pese o conturbado contexto de emergência desse acontecimento, ele parece ter se constituído num dispositivo importante no processo de diferenciação que nos separa da organização do ensino superior de outros países latino-americanos, como Argentina e Uruguai, abrindo caminho para posteriores políticas de apoio à formação pós-graduada, bem como de profissionalização e carreira dos docentes no ensino superior.

5 In Brovetto, Rojas Mix e Panizzi (orgs.), 2003. Destaque-se, por outro lado, na esteira da Internet, a iniciativa de criação e fortalecimento da RNP (Rede Nacional de Pesquisa) no Brasil, em termos de política e planejamento estratégico.

6 Cf. Brovetto, Rojas Mix e Panizzi, 2003.

7 Cf. Marco Antonio Rodrigues Dias, 2003. 
Axt, $M$.

"O pesquisador frente à avaliação na pós-graduação: em pauta novos modos

de subjetivação"

4) os sucessivos modelos de avaliação implantados pelas agências de fomento da Pós-Graduação e da Pesquisa, culminando no atual COLETA CAPES, implementado desde 1998, inclusive, em alguns momentos, um tanto enviesadamente, com mudança de regras em meio aos processos de avaliação dos Programas, quando estes já haviam entregado seus relatórios de acordo com regras então vigentes. Isso ocorreu pelo menos duas vezes: na avaliação do biênio 1996-7 (em fevereiro de 1998), por conta da implantação do Núcleo de Referência Docente - NRD - que magnificou um núcleo permanente de docentes que deveriam ter título de doutor; e, mais seriamente, na avaliação do triênio 1998-2000 (em maio/junho de 2001, quando as avaliações pelas Comissōes de Área já se encontravam em curso, algumas mesmo já concluídas), com o objetivo de regular a posteriori os conceitos 6 e 7, tendo como carro-chefe a inserção internacional da produção docente proporcional de cada Programa e que foi estipulada em $17 \%$ para conceito 6 (seis) e $30 \%$, para conceito 7 (sete) $;^{8}$

5) a sensibilidade das Agências de Fomento aos conceitos avaliativos exarados com relação aos Programas PG, os mesmos passando a regular, desde 1998, praticamente todas as regras do fomento - quotas de bolsas dos Programas, recursos de custeio e capital...

8 Com relação a este ponto, coordenadores de Programas PG à época questionavam os índices estabelecidos, perguntando como surgiram estes parâmetros para definir a tão decantada "inserção internacional" e se a mesma pode ser avaliada em dados percentuais tão relativos?! Pois, afinal, como colocavam alguns, $17 \%$ de 100 são 17 , mas $17 \%$ de 50 são 8,5 , evidenciando o quão fácil é manipular a avaliação através de índices percentuais. Como se tal não bastasse, e exatamente por isso, é de se perguntar: por que o CTC/CAPES esperou que as comissões de algumas áreas concluíssem suas avaliações para só então estabelecer os percentuais de inserção internacional que definiriam Programas 6 e 7? (observaçôes de coordenadores de Programas PG, no Brasil, retiradas de levantamento divulgado em lista de discussão na UFRGS).

9 Cumpre lembrar que os Programas de fomento, como PROF/CAPES, têm constituídas Comissões de Gerenciamento dos Recursos, internas às IES, que, entre vários critérios, não deixam de considerar o Conceito do Programa definido pelo CTC/CAPES, como um critério importante na distribuição dos recursos entre os diversos Programas PG da IES. 
6) a sensibilidade do modelo avaliativo implantado a informaçôes de caráter quantitativo, como grau de impacto atribuído a veículos de publicização da produção científica (periódicos, encontros científicos...);

7) a orientação e a regulação do modelo avaliativo por uma lógica competitiva, individualista, disciplinar, homogeneizantez e excludente, gerando todo um processo de definição e de normalização da Excelência em Pós-Graduação e em Pesquisa.

10 Observe-se que o grau de impacto de periódicos e de eventos científicos é medido, negativamente, pelo número de trabalhos não aprovados em proporção aos aprovados, o que, mais uma vez, torna o indicador sensível à manipulação. $\mathrm{Na}$ medida em que organizadores podem definir, como regra, um mínimo de trabalhos a serem aceitos por evento ou número de periódico, a conseqüência natural parece ser, cada vez mais, uma elitização desses espaços, ao invés de sua democratização. Acresça-se a isso a exigência de os pesquisadores publicizarem seus trabalhos continuamente de acordo com índices de produtividade previamente estabelecidos pela área e teremos uma avalanche de submissões seguidas de poucas aprovaçóes, com decorrente geração de alto grau de impacto.

11Como lembra Odair Dias Gonçalves (2003), a Pesquisa e a PG no Brasil são atividades afetas a dois ministérios - a pesquisa, ligada ao CNPq, é gerenciada pelo Ministério de Ciência e Tecnologia (MCT), enquanto a supervisão da PG, cabe à CAPES, órgão do Ministério da Educação, Cultura e Esportes (MEC) -, gerando muitas vezes "duplicação de atribuiçôes e duplicidade na alocação de recursos exigindo um aumento do controle que poderia ser dispensável" (grifo meu). Este controle, que vem, através da própria reivindicação (antiga) da comunidade acadêmica, acabou gerando, no entanto, conforme o pensamento de Odair D. Gonçalves, dois efeitos indesejáveis: (1) na medida em que, para compor as várias representações nesses órgãos, os representantes da comunidade são indicados pelas Sociedades Científicas e Conselhos Profissionais - estes, eu diria, quase sempre compromissados com os indicadores de produtividade e de excelência de sua área e, cf. a autora, representando segmentos de cada árealprofissāo, nem sempre majoritários e onde nem sempre existe diversidade de opiniāo -, nem sempre são levadas em conta diferenças individuais e de visão de ciências ou de prática profissional nas instituições, o que pode gerar restriçôes de potencialidades institucionais ou de linhas de pesquisa; (2) a avaliação por pares, sendo um sistema altamente desejável, necessário e reconhecido hoje internacionalmente, enfrenta, no entanto, no Brasil, na visão da pesquisadora citada, algumas dificuldades, na medida em que avaliações de projetos têm muitas vezes sido feitas com base no currículo do pesquisador, mas a partir das reduçôes continuadas de verbas: nesse sentido, o programa de bolsas $\mathrm{PQ} / \mathrm{CNPq}$ - produtividade -, por exemplo, é crítico, pois estaria muito dependente da figura do avaliador; e uma vez que o pesquisador tivesse recebido uma classificação dada pelo respectivo comitê de avaliação, ela começaria a ser adotada no país como medida da qualifica- 
Axt, $M$.

"O pesquisador frente à avaliação na pós-graduação: em pauta novos modos

de subjetivação"

ALGUNS DESDOBRAMENTOS ATUAIS - PROCESSOS DE SUBJETIVAÇÃO

Dessas linhas que nos chegam com seus efeitos diversos, configurando um complexo contexto neste aqui-e-agora de pelo menos alguns Programas brasileiros de Pós-Graduação e seus pesquisadores, trago, para discutir, três desdobramentos, tal como os consigo capturar em uma primeira tentativa de deslindamento do $N o ́$, ainda que, talvez, de modo um tanto impreciso ou parcial, buscando, apesar disso, dar-lhe um contorno de cena em curso, visto da perspectiva do pesquisador:

a. Os indicadores de produtividade do pesquisador - estipulado pelos pares, os indicadores regulam o quanto, e como, cada um precisa produzir anualmente, tenha, ou não, obtido resultados (ou resultados suficientes) de pesquisa; e independentemente de seu modo/estilo de produção, ou de suas preferências (artigos, livros, capítulos de livros etc.). Atualmente, os indicadores de quantidade e qualidade são definidos pela área de conhecimento à qual se vincula o pesquisador. E quando o pesquisador atua numa interface entre áreas de conhecimento que regulam diferentemente a excelência da produção intelectual (como por exemplo, pesquisadores que atuam na interface entre educação - que prioriza livros, capítulos de livros - e informática ou algumas psicologias - que enfatizam, respectivamente, apresentações em congressos internacionais e artigos em periódicos -, o que se pode fazer? E quando o pesquisador (justamente por produzir numa interface, entre duas áreas de conhecimento) atua em dois Programas de PG e precisa direcionar sua produção a este ou a aquele Programa, exclusivamente? Ou, então, precisa fragmentar sua produção dividindo-a entre ambos Programas, em virtude de

ção do pesquisador, gerando efeitos de propagação da mesma, excluindo ou incluindo o referido pesquisador quase que a priori, do/no sistema, contemplando predominantemente os mesmos com novos financiamentos e assim aumentando a distância entre grupos de pesquisa consolidados e emergentes, o que obviamente se reflete no currículo do pesquisador, para bem e para mal. 
uma normalização do modelo avaliativo que considera, não o pesquisador enquanto autor de uma determinada produção, mas a quantificação dos produtos, estes sendo alienáveis e alienados do seu autor e do processo de produção? ? $^{12} \mathrm{O}$ que se pode fazer quando dita produção se encontra ancorada em grupo de pesquisa com integrantes de ambas áreas de conhecimento, e, portanto, nem mais nem menos representativa de uma ou outra área, mas hibridizada por ambas!? Cabe destacar que tal normalização vem ocorrendo justamente em um momento, no cenário contemporâneo da pesquisa, em que se começa a concluir que não é mais possível trabalhar apenas nos limites estreitos da disciplinaridade, que o conhecimento é regido por princípios de complexidade não contemplados pelas disciplinas isoladamente: estão aí novos campos disciplinares, como a físico-química, a biofísica etc., exemplos vivos do aproveitamento (e já da cristalização) de um possível anterior conhecimento transdisciplinar (para além das disciplinas), este por sua vez historicamente delineado - de modo instável e até imprevisível - a partir de estudos iniciais multi-interdisciplinares às vezes tão pouco considerados nas áreas de origem.

12 Embora os docentes possam atuar em dois programas de pós-graduação, no momento de contabilizar sua produção intelectual para fins de avaliação e relatório CAPES, tem havido, hoje, uma exigência contraditória de que o pesquisador divida a sua produção entre os dois programas, com isso penalizando, não apenas o pesquisador em termos quantitativos, mas os cursos em que atua. Mas o problema mais sério que aí vejo, principalmente quando se trata de pesquisadores que atuam de modo simultâneo em Programas na categoria "Multidisciplinar", é o de que o pesquisador possa ser penalizado na própria qualidade do seu trabalho. $\mathrm{O}$ esforço inter/transdisciplinar de sua pesquisa é a fortiori ignorado na contabilização e divisão quantitativa, exigindo dele algo que não pode fazer - dividir entre dois cursos aquilo que é resultado da integração dos conhecimentos e dos recursos humanos buscados nos dois cursos. Orientandos dos dois cursos integram o grupo de pesquisa. E os trabalhos publicados resultam do esforço e do conhecimento gerado em ambos os cursos.

13 Basta examinar os Qualis de algumas (não todas!) áreas para confirmar a exclusão de periódicos multi-interdisciplinares. 
Axt, $M$.

"O pesquisador frente à avaliação na pós-graduação: em pauta novos modos de subjetivação"

b. Os indicadores de qualidade, definidos pelos QUALIS de cada área - estes normalizam os espaços de publicização (eventos científicos e veículos de publicação) da produção dos pesquisadores. O que fazer, a título de ilustração, em áreas como a de Educação ou a de Saúde Pública, quando a ênfase do modelo avaliativo passa a ser na decantada "inserção internacional”? Educação e Saúde Pública são áreas que trazem intrínsecas à sua prática uma vocação para a discussão das problemáticas locais-regionais em suas singularidades, num processo de socialização contínua das estratégias alternativas de avaliação-intervenção nos contextos em foco, e muitas vezes sem ambição de universalização. Se há temáticas e setores, em áreas como essas, que se prestam a publicações de abrangência maior, outras há que ficam deslocadas e mesmo desvirtuadas a partir de tal exigência. $O$ provável público leitor de nível internacional, passando a ser mais requintado teóricametodologicamente, acaba por exigir do texto que a linguagem se sofistique, o jargão se tecnicize, os conceitos se complexifiquem, fugindo à compreensão dos leitores comuns, por exemplo, profissionais em serviço na ponta da formação, na Educação Básica ou nos postos de saúde respectivamente... ${ }^{14}$ Se há algum índice de impacto para medir, este deveria dizer também do compromisso ético para com as transforma-

14 Com relação aos Periódicos Internacionais, outro ponto destacado por coordenadores de Programas PG, de diferentes áreas do conhecimento, é que este tipo de avaliação leva pesquisadores de nossas Instituições a publicarem seus trabalhos na língua inglesa e em revistas estrangeiras, mesmo que suas pesquisas, financiadas com recursos públicos Brasileiros, estejam direcionadas a problemas caracteristicamente brasileiros e de interesse para profissionais brasileiros. Como pergunta um coordenador de PPG da área da saúde: será que baseado neste tipo de avaliação não poderá haver um direcionamento de nossas prioridades de pesquisas para problemas internacionais em detrimento dos nacionais? Ele chama a atenção de que em 1997, o Prof. Foratini, em um editorial (Foratini, O.P. A internacionalidade da ciência. Rev. Saúde Pública, 31(2): 115, 1997), já demonstrava preocupação com esta tendência dizendo que "a falta do pretenso caráter internacional leva ao demérito ou à classificação do trabalho como subdesenvolvido, de terceiro mundo, desinteressante..." e que "no afā de internacionalizar as próprias atividades de pesquisa, muitas vezes presta-se desserviço à própria população que as custeiam". $\mathrm{Na}$ opinião do referido coordenador, publicaçôes em periódicos "internacionais", 
ções propiciadas pelo conhecimento sobre as Realidades estudadas e para com a dimensão multiplicadora das possibilidades de transformação; que esta dimensão possa atingir um patamar de internacionalização do conhecimento gerado, pode ser desejável e até necessário, mas questiona-se se deve ser a questão dominante, sob pena de que se possa, às custas das realidades dramáticas do país, estar gerando conhecimento em prol de um calculado (às vezes, duvidoso) benefício acadêmico. ${ }^{15}$ Ao mesmo tempo, como faz o pesquisador, atuando na interface das disciplinas, quando o Qualis de uma área de origem não pontua favoravelmente publicações em periódicos e em encontros de caráter interdisciplinar, por exemplo?

ou melhor "estrangeiros", devem ser estimuladas quando pertinentes, mas esta não deve ser quantificada e utilizada como um critério (dominante, eu diria) para avaliação, visto que nossas linhas e projetos de pesquisa na sua grande maioria versam sobre assuntos de interesse nacional. É pertinente notar que esta política reduz a importância dos periódicos nacionais. Da mesma forma, outro coordenador da mesma área se pergunta que interesse terá para profissionais de outros países as relações da Pesquisa (e da PG) com o SUS brasileiro, por exemplo, embora para os estudiosos do Brasil, esta matéria tenha real interesse e devesse ser amplamente debatida em periódicos regionais e nacionais (observações de coordenadores de Programas PG, no Brasil, retiradas de levantamento divulgado em lista de discussão na UFRGS; os grifos são meus).

15 Somente a título de exercício reflexivo, e hipoteticamente, pergunto o quanto pesquisas feitas para apenas serem publicadas em revistas internacionais ou estrangeiras, que tenham como fulcro, por exemplo, a nossa população de "Meninos de rua" ou a dos "Povos da floresta", determinarão efetivamente mudanças no panorama mundial, principalmente se os resultados de tais pesquisas denunciarem como contexto estrutural as determinaçôes dos modelos econômicos mundiais vigentes há décadas... talvez não sejam nem aceitas para publicação (cf. relatos no interior de GT da ANPEPP, por pesquisadora da área)!? Por outro lado, quanto impacto poderiam ter se publicadas no âmbito de nossas realidades regionais, nacionais, ao atingirem e sensibilizarem profissionais, estudiosos e pesquisadores da área, chefias, coordenaçốes...

16 Ver documento de Área, elaborado pela Comissão de Avaliação CAPES da Área de Ciência da Computação, a título de exemplificação da questão específica: Periódicos de área nacionais não contemplados no indexador internacional CiteSeer (Computer Science Research Index - http://citeseer.nj.com/impact.html) não são classificados. Periódicos de outras áreas (não-afins): se estiverem indexados é C, caso contrário, não são classificados (o que, em princípio parece que estaria ferindo um "acordo de cavalheiros" entre as diferentes Comissôes das Áreas, que se propõem a aceitar a avaliação e a classificação obtidas nos QUALIS das outras áreas). 
Axt, $M$.

"O pesquisador frente à avaliação na pós-graduação: em pauta novos modos de subjetivação"

c. A ressuscitada taxa de bancada do $\mathrm{CNPq}$ - a taxa de bancada por quota de bolsa (contrapartida do fomento à instituição que atende ao bolsista) havia sido suspensa em 1998, quando tinha a seguinte formulação: a taxa de bancada, relativa às bolsas de doutorado, no primeiro ano revertia ao Programa, que socializava o recurso atendendo a demandas de pesquisadores e alunos do curso; nos anos subseqüentes, a taxa de bancada deveria reverter ao orientador tendo em vista apoiar e subsidiar as açóes do respectivo grupo de pesquisa. Nem bem começava a ser posta em prática, esta política foi abortada pela suspensão do benefício. O ressuscitamento dessa política no ano de $2003^{17}$ deu-se pelo desembolso do benefício diretamente na conta do doutorando, configurando um recurso importante, é verdade, para os bolsistas que, a cada três meses, somam o equivalente a uma bolsa mensal de doutorado, mas, de um certo ponto de vista, privatizou o recurso. ${ }^{18}$ Essa política enviesada cria, de saída, doutorandos de primeira e de segunda categorias: ${ }^{19}$ os que recebem apoio para deslocar-se e assim integrar-se às redes de pesquisa institucionalizadas através dos encontros da comunidade científica na área de interesse, e os que à partida, sem recursos, estão excluídos desse processo, a não ser que compensem tal política por um dobrado esforço. Do mesmo modo, esta política pode contribuir para criar um fosso no interior do grupo de pesquisa, na medida em que é passível de desestabilizar as relaçôes de equanimidade, instituindo relaçôes de força e poder que, é bastante provável,

17 Ofício Circular no 0141-03/PRE/CNPq.

18 Em Of. n $134 / 03-P R O P G$ endereçado ao Presidente do CNPq - Prof. Erney Plessmann de Camargo -, a então Pró-Reitora de Pós-Graduação/UFRGS, com o apoio do fórum de coordenadores de Programas PG/UFRGS, considera, sob a ótica institucional, que o número de bolsas de doutorado CNPq alocadas aos Programas de Pós-Graduação, na UFRGS, deverá contar, pelas taxas de bancada, com um montante adicional de recursos anuais, em torno de 2 milhões de reais, só nesta IES, que permanecerão sem a menor perspectiva de planejamento para uma utilização socializada e conseqüentes benefícios institucionais.

19 No mesmo ofício (nota 16), a Pró-Reitora enfatiza que se criarão, também entre os bolsistas, duas classes de bolsistas - CAPES e CNPq, provocando disputas no momento de alocação das bolsas para este ou aquele candidato. 
talvez trabalhem em médio prazo no sentido de uma implosão das relações de cooperação entre os integrantes dos grupos de pesquisa, calcadas nas possibilidades efetivas de co-autoria. Finalmente colocam o próprio pesquisador orientador numa situação desconfortável, e por que não dizer, até humilhante, na medida em que ele, para participar de um evento na área, necessita (por falta de autonomia em termos de recurso) solicitar auxílio-evento às agências de fomento e submeter-se às avaliaçôes dos pares quanto à legitimidade de seu pleito, mesmo tendo trabalhos seus aprovados no referido evento, enquanto seu orientando tem autonomia para tomar tais decisões. Ora, isso tende a subverter as relações entre orientador-orientando, em médio prazo, indignando os pesquisadores que talvez passem novamente a se fechar em seu individualismo, logo num momento em que, pelo menos em áreas e sub-áreas como a de Educação, orientadores e orientados começavam a estabelecer interessantes relações de cooperação nas pesquisas, socializando projetos, ações e produção decorrente, em processos de co-autoria, quando antes isso não fazia parte da cultura da área. Este estado de coisas tende a se reproduzir no que diz respeito aos recursos para a pesquisa de campo, tanto no que refere aos orientados bolsistas e não bolsistas, ou bolsistas CNPq e bolsistas CAPES, dentro do grupo de pesquisa, quanto no que remete às condiçóes diferenciadas para pesquisa de campo para orientador e orientando bolsista (quando orientador não tem, por exemplo, aprovados seus pedidos de recurso para pesquisa, em virtude de situações como as discutidas nos itens (a) ou (b) acima).

\section{O MODO PESQUISADOR FRENTE À AVALIAÇÃO DA PG - SUBJETIVAÇÃO E DEVIR}

Estas cenas perspectivadas, mas produzidas historicamente, são trazidas para análise tendo em vista projetar uma atualização possível a partir do $N o ́$ crítico instaurado nesse contexto de linhas tão emaranhadas: não se pode deixar de pensar que uma via de atualização de nosso Presente no devir possa ser dar passagem a um processo 
Axt, $M$.

"O pesquisador frente à avaliação na pós-graduação: em pauta novos modos

de subjetivação"

crescente e irreversível de sistemático estraçalhamento do pesquisador em diferentes níveis: (a) no interior do Programa, ao não estar em conformidade com os índices de qualidade formulados; ${ }^{20}$ (b) na sua própria área de atuação, pela normalização draconiana dos QUALIS, em especial quando atuando nas interfaces e/ou atuante em dois Programas de PG, quase sempre à custa de uma sobrecarga de trabalho (assiste-se aí à penalização do pesquisador quando do seu desapego a um certo pragmatismo que regula a vida acadêmica); (c) no interior de seu grupo de pesquisa, assistindo impotente a um possível desmantelamento, em médio prazo, pela instauração de assimetrias incongruentes nas relações de troca e de cooperação acadêmica.

20 Considere-se, neste particular, além das questões já referidas e discutidas nesta proposta reflexão, também a sobrecarga do docente nas universidades públicas, tanto administrativa, quanto de docência na graduação - e que, se por um lado, apresenta vantagens relacionadas à integração do conjunto dos processos de formação, por outro lado restringe o tempo e o espaço de produção bibliográfica desse pesquisador. Ministrar aulas nos cursos de graduação tem sido obrigatório para docentes nas IES públicas, mas pouco valorizado na avaliação CAPES em termos de pontuação, embora esta articulação seja das mais importantes para a formação de uma massa crítica nas universidades.

21 Essa obsessão por pontuação em relação a veículos de difusão da produção científica, bem como a exigência de que cada pesquisador seja avaliado com relação à quantidade de publicações e à abrangência de circulação dos veículos nos quais publica (nacional, internacional, local) sugerindo que quanto maior a abrangência maior o nível de qualidade da publicação, está começando a levar a uma perigosa homogeneização, não apenas dos veículos de difusão da produção científica, mas dos próprios trabalhos publicados, aumentando a quantidade informacional (não necessariamente em qualidade ou em conhecimento novo) de maneira geométrica, mas ao mesmo tempo afastando o pesquisador das realidades concretas e dos profissionais na sociedade comum que dependem diretamente do seu conhecimento. 22 É no trabalho dentro do grupo de pesquisa que se formam os novos pesquisadores de maneira mais completa. E é também um trabalho que demanda mais dedicação do pesquisador orientador. No entanto, uma conseqüência direta desse trabalho desenvolvido conjuntamente - a produção bibliográfica em co-autoria, dando conta da organicidade do trabalho em relação à Linha de pesquisa -, não sendo devidamente valorizada, seja pelo modelo de avaliação vigente (como ocorre em algumas áreas, na avaliação CAPES), seja pelas assimetrias artificialmente produzidas pelo fomento (como a da taxa de bancada), pode ser despotencializada: um "efeito colateral" incidiria sobre a formação de jovens pesquisadores no que diz respeito à cooperação através de redes de pesquisa, pois o pesquisador jovem poderá decidir que o que tem 
Parece urgente que haja uma democratização dos parâmetros de avaliação. Precisa-se de parâmetros para avaliação, é certo! E a avaliação, como condição de crescimento e de avanços na excelência, é necessária e indispensável! Não seria esta, no entanto, a questão principal. Deslocando um pouco o foco da questão, poder-se-ia colocar que, se a avaliação é condição necessária para o crescimento da excelência na Pesquisa e na formação Pós-Graduada, não é, contudo condição suficiente. Uma certa autonomia para tomada de decisóes quanto a aspectos a serem valorizados pelo próprio Programa, ou quanto ao estilo de ser pesquisador de cada integrante de Programa de PG, são elementos que podem e devem passar pela avaliação, mas talvez não por uma avaliação distribuidora de conceitos ditos objetivos que criam "rankings" de maior ou menor competência; e sim, talvez, avaliaçõos descritivas, qualitativas, que levem em conta a História de avanços de cada Programa na busca de sua própria excelência, não necessariamente igual a de todos os demais; avaliaçōes que apontem de forma madura o que nos Programas, em cada um, precisa melhorar ou mudar, na busca dessa excelência, e que o Programa tenha voz e possa ser escutado, estabelecendo-se então um diálogo com os avaliadores, ${ }^{23}$ em que a meta seja a produção dessa mesma excelência, e não a enunciação de vereditos/sentenças, sejam eles redentores ou condenatórios. Nessa dimensão, com certeza perder-se-á o ranking, ficando mais difícil a distribuição de recursos, mas talvez esta seja uma política mais justa, que ajude mais a Pós-Graduação e a Pesquisa no Brasil.

Da forma como está, parece que uma política de homogeneização vem se instalando com relação às diferentes áreas do conhecimento representadas na CAPES, permanecendo, tão somente, uma oposição mais geral entre paradigmas de ciência (principalmente, mas não só, a oposição Ciências naturais/humanas), em que um paradigma

mais valor não é propriamente a cooperação em rede e a co-autoria, mas a produção individual (o que viria na contramão do que estava sendo proposto pela política dos editais $\mathrm{CNPq}$ até há pouco tempo).

23 Interessante observar que nas avaliaçóes em meio a cada triênio - denominadas de processo de avaliação continuada - tal proposta já vem sendo viabilizada pelas Comissões de Avaliação CAPES das diferentes áreas. Essa idéia não é nova, tem sido enunciada por outros colegas pesquisadores. 
Axt, $M$.

"O pesquisador frente à avaliação na pós-graduação: em pauta novos modos

de subjetivação"

dominante em relação ao outro, acaba por produzir uma cultura de desvalorização referente ao paradigma não dominante, pela definição de parâmetros vetorializados e de pontuações diferenciadas, determinando o que é o melhor para a Pós-Graduação, o que é o mais correto em Pós-Graduação! É este estado de coisas que contribui para levar, por suposto, a uma política de criação de rankings que, atrelada à política da distribuição de recursos (em especial quotas de bolsas para os cursos e para os projetos de pesquisa), vai levando a uma ameaçadora pasteurização da Pós-Graduação no país, além de uma competição violenta pelos parcos recursos. Uma infeliz conseqüência, no limite, poderia ser a convergência massificadora da formação do pesquisador, a falta de criatividade e de iniciativa quanto a novas possibilidades...

Retomam-se, com toda a força das linhas duras na instância macropolítica, as políticas de valorização individualizante pelo lucro, pelo jogo competitivo, interditando, na instância micropolítica, modos existenciais de ser pesquisador, de ser professor em PG enquanto orientados pelas frágeis linhas do cuidado com a vida, do cuidado com relações de convivência, calcadas na cooperação mútua; calcadas na generosidade da socialização do conhecimento e dos encantos propiciados pelos processos coletivos de criação: enfim, relações calcadas na preservação de uma ecologia da diversidade, da reciprocidade, da solidariedade.

No entanto, se lembrarmos o início desse texto, a passagem que projeta o futuro ainda não se efetivou, o passo ainda não foi dado, o pé ainda se encontra no ar, experimentando quais linhas o acompanham, estendendo-se mais ou menos no passo que vai dar para fazer território. Cabe-nos criar condições de possibilidade na instância micropolítica para, com base em avaliaçôes coletivas de conjunto, propor estratégias de intervenção também coletivas, ocupando espaços de publicização, trabalhando no engendramento de novos agenciamentos, na contracorrente do pensamento homogêneo, individualizante e de competição excludente. Tais movimentos agenciados na instância das relações micropolíticas podem adquirir força de potência, podem provocar a emergência, na instância macropolítica de modelos de avaliação mais contemporâneos, calcados no respeito à diversidade, na consideração do tempo enquanto multiplicidade, perspectivando questôes científico-políticas na dimensão do seu compromisso com uma ética-estética. 


\section{REFERÊNCIAS}

AUGÉ, Marc. Não-lugares. Papirus, 1994.

BROVETTO, Jorge; ROJAS MIX, Miguel; PANIZZI, Wrana Maria (Orgs.). A educação superior frente a Davos, Porto Alegre, UFRGS, 2003.

BROVETTO, Jorge; ROJAS MIX, Miguel; PANIZZI, Wrana Maria. La educación superior frente a Davos. In: BROVETTO, Jorge; ROJAS MIX, Miguel; PANIZZI, Wrana Maria. (Orgs.). A educação superior frente a Davos, Porto Alegre, UFRGS, 2003.

DELEUZE, Gilles. Bergsonismo. S.P.: Ed. 34, 1999.

DELEUZE, Gilles. Diferença e Repetição. R.J.: Graal, 1988.

DIAS, Marco Antonio Rodrigues. A OMC e a Educação Superior para o Mercado. In: Jorge BROVETTO, Miguel ROJAS MIX e Wrana Maria PANIZZI (Orgs.). A educação superior frente a Davos, UFRGS, 2003.

DOCUMENTO DE ÁREA. Área Ciência da Computação, Avaliação CAPES, 2001.

GONÇALVES, Odair Dias. Apud DOCUMENTO DE ÁREA. Área Multidisciplinar, Avaliação CAPES, 2003.

SANTOS, Boaventura de Sousa. Um discurso sobre as Ciências. Porto, Afrontamento, 1999.

Margarete Axt, é Doutora em Educação, Professora junto ao Programa de Pós-Graduação em Educação da Universidade Federal do Rio Grande do Sul. $O$ endereço eletrônico da autora é: maaxt@ufrgs.br

Margarete Axt

$\mathrm{O}$ pesquisador frente à avaliação na pós-graduação: em pauta novos modos de subjetivação

Recebido: 8/11/2003

Aceite final: 8/1/2004 
Coimbra, C. M.

"Tensão ou oposição entre ciência e política na pós-graduação? um falso problema?"

\title{
TENSÃO OU OPOSIÇÃO ENTRE CIÊNCIA E POLÍTICA NA PÓS-GRADUAÇÃO? UM FALSO PROBLEMA?
}

\author{
Cecília Maria Coimbra \\ Universidade Federal Fluminense
}

RESUMO: Resistindo, denunciando, cansando, algumas vezes indignando-nos, a maioria do tempo estamos vivendo os extertores da universidade pública brasileira, em especial na área conhecida como Ciências Humanas e Sociais. Dentro do ideário neoliberal de Estado mínimo os recursos e financiamentos que têm sido alocados na educação superior pública e laica, em nosso país são, a cada ano, mais irrisórios. Interessa que, numa mesma universidade pública, os vários centros, institutos e departamentos se degladiem ferozmente entre si pelas verbas repassadas em migalhas e vindas como esmolas. As equipes, os professores e alunos competem uns com os outros pelos, cada vez mais, escassos financiamentos. São estas observaçōes que trago neste texto como notas introdutórias sobre a questão da universidade brasileira hoje, em especial, no que se refere ao sucateamento que vem sofrendo a chamada área de "humanidades", nos cursos de pós-graduação.

PALAVRAS-CHAVE: universidade pública, política, ciências sociais e humanas.

TENSION OR OPPOSITION BETWEEN SCIENCE AND POLITICS IN THE POSTGRADUATE? A FALSE PROBLEM?

ABSTRACT: Resisting, denouncing, tiring, sometimes becoming indignant, most of the time we are living the final moments of Brazilian public Universities, specially in the area known as Social and Human Sciences. In the neoliberal ideal of minimum State, the resources and financings that have been allocated in public collegeeducation in our country are, each year, more insignificant. It interests that, in a same public university, the several centers, institutes and departments ferociously struggle among themselves 
for the amount of money repassed in crumbs and coming as almses. The teams, the professors, the students compete against each other for the rare financings. These are the comments I bring in this text as introductory notes on the issue of Brazilian Universities today, specially concerned with devastation that, the so called "humanity" area has been suffering in Post-Graduation courses.

KEYWORDS: public university, politics, social and humans sciences.

Nas universidades, o que prevalece é o modelo de administração eficiente, capaz de gerar seus próprios recursos estabelecendo nexos cada vez mais profundos com o mercado e a corrida tecnológica. A eficácia do desempenho é medida em termos de sucessos estatísticos, de capitais, produtividade e visibilidade, todos conversiveis em valores de marketing para atrair novas parcerias, dotaçôes $e$ investimentos. (Nicolau Sevcenko)

Aos trancos e barrancos, resistindo - nem sempre utilizando as estratégias mais produtivas - denunciando, cansando - algumas vezes - indignando-nos - a maioria do tempo - estamos vivendo os extertores da universidade pública brasileira, em especial na área conhecida como Ciências Humanas e Sociais.

Estas observações que aqui trago são apenas pequenas notas introdutórias sobre a questão da universidade brasileira hoje, em especial, no que se refere ao sucateamento que vem sofrendo a chamada área de "humanidades", nos cursos de pós-graduação.

Dentro do ideário neoliberal de Estado mínimo os recursos e financiamentos que têm sido alocados na educação superior pública e laica, em nosso país são, a cada ano, mais irrisórios.

Interessa que, numa mesma universidade pública, os vários centros, institutos e departamentos se degladiem ferozmente entre si pelas verbas repassadas em migalhas e vindas como esmolas. As equipes, os professores e alunos competem uns com os outros pelos, cada vez mais, escassos financiamentos.

1 Termo utilizado pelo prof. Osvaldo Coggiola que aponta sua utilização como uma inclinação para destituir as ciências humanas de seu caráter científico. 
Coimbra, C. M.

"Tensão ou oposição entre ciência e política na pós-graduação? um falso problema?"

O professor ideal agora é um híbrido de cientista e corretor de valores. Grande parte de seu tempo deve ser dedicado a preencher relatórios, alimentar estatísticas, levantar verbas e promover visibilidade para si e seu departamento. O campus vai se configurando num gigantesco pregão (...). (SEVCENKO, 2000:7)

A universidade pública e laica, funcionando aos moldes de uma empresa capitalista - onde fazer pesquisa tem sido, antes de mais nada, o aumento abusivo de obrigaçōes burocráticas ${ }^{2}$ (informes, questionários, ênfase quantitativa em trabalhos que não serão lidos) - vem priorizando, não por acaso, através de seu órgãos financiadores de pesquisa, as chamadas ciências exatas e biológicas.

Ou seja, o sucateamento, o aviltamento da educação superior pública e laica em nosso país são agravados quando nos referimos às ciências humanas e sociais. Estas, em especial, a nível de pós-graduação, vêm sendo subalternizadas, desqualificadas e inferiorizadas em relação a outras áreas de conhecimento. ${ }^{3}$ O conhecimento tecnocrático, fundamento do próprio sistema capitalista, impõe-se como o melhor, o que deve merecer atenção e, portanto, ser priorizado.

Dentro do ideário racionalista - onde a reificação da ciência, enquanto instrumento objetivo e percebido como capaz de fornecer conclusões exatas, formular prognósticos confiáveis, em suma, "ge-

2 Um exemplo do arbítrio e da intolerância burocrática foi o que aconteceu comigo na Universidade Federal Fluminense, onde trabalho. Por erro, ao solicitar à PróReitoria de Pesquisa bolsas de iniciação científica do CNPq para dois alunos que comigo desenvolviam um projeto de pesquisa, em lugar do meu Currículo Lattes (única formatação de currículo hoje aceita) foi enviado um outro curriculum vitae das minhas atividades profissionais - uma outra formatação. As bolsas foram negadas sob o argumento de que um documento exigido no edital não foi apresentado e nem poderia mais ser aceito pois o prazo havia expirado. Durante um ano tive dois alunos pesquisando comigo sem bolsas do $\mathrm{CNPq}$, o que não só é um direito desses alunos, como pesou negativamente na minha avaliação de produtividade: eu não possuía alunos bolsistas oficiais.

3 Sobre este tema em especial consultar os vários artigos constantes na Revista da Adunicamp "Universidade e Humanidades" (2002), fruto de um seminário realizado, em abril de 2002, por essa entidade docente. Muitos desses artigos serão citados no decorrer destas notas introdutórias. 
rar tecnologias" - entende-se perfeitamente essa opção que vem, nos últimos quinze anos, sendo feita para as áreas tecnológicas e, não por acaso, chamadas de ciências exatas.

O "tecnicismos cientificista", estimulado pelo pensamento cartesiano dominante na academia e pela crença na razão universal, em muito tem servido ao sistema capitalista. Silva (2002:6) a isto se refere ao apontar que:

A humanidade jamais conheceu um sistema econômico capaz de gerar - de forma permanente e estrutural - tanta miséria e desigualdade social. Isso talvez explique a ausência de uma discussão minimamente razoável sobre o conhecimento tecnocrático, fundamento do próprio sistema capitalista. Este conhecimento se impóe pela força da ideologia dominante, sob o charmoso tacão da grande midia, mas também a golpes de critérios de rendimento e produtividade de governos e agências governamentais de fomento ao ensino e à pesquisa - critérios que a maioria da comunidade acadêmica acata, raramente com entusiasmo, por vezes constrangida, quase sempre em silêncio.

Talvez seja otimista a avaliação feita por Silva, ao assinalar o pouco entusiasmo, o constrangimento e, mesmo, o silêncio da comunidade acadêmica aos ditames dos financiamentos que vêm sendo repassados, em especial às áreas humanas e sociais. O que temos presenciado, de forma clara e explícita, é a adesão a tais ditames; é o reconhecimento e o acatamento de que determinadas pesquisas, em determinadas áreas, são menos nobres, e têm, portando, menor valor acadêmico. Aceita-se o "pesquisador de segunda classe" (NOBRE, 2002), aquele que vale menos intelectualmente e academicamente e, portanto, menos financeiramente.

Deleuze (1992:221) ao nos falar das sociedades contemporâneas que denominou de sociedades de controle, a isso se refere ao afirmar que:

(...) a empresa introduz o tempo todo uma rivalidade inexplicável como sã emulação, excelente motivação que contrapõe os individuos entre si e atravessa cada um, dividindo-o em si mesmo. O prin- 
Coimbra, C. M.

"Tensão ou oposição entre ciência e política na pós-graduação? um falso problema?"

cípio modulador do "salário por mérito" tenta a própria Educação Nacional: com efeito, assim como a empresa substitui a fábrica, a "formação permanente" tende a substituir a escola, e o controle contínuo substitui o exame. Este é o meio mais garantido de entregar a escola à empresa.

Um outro fator tem agravado, em especial, a situação das áreas humanas nas universidades brasileiras, sobretudo, a partir de 1994: o número crescente de aposentadorias, em função do pânico gerado no funcionalismo público, em geral, e nos docentes, em particular, pelas ameaças de reforma do Sistema Previdenciário. Dentro do vendaval neoliberal, as universidades, públicas em especial, perdem seus professores e desmontam-se grupos inteiros de pesquisa e extensão. Alguns levantamentos realizados atestam para o assustador número de professores que pedem afastamento dos estabelecimentos públicos e migram para os particulares, onde os salários são três vezes maiores. A saída desses docentes, em especial nas áreas humanas, não tem tido substituição, crescendo com isso o número de vagas de professores nessas áreas.

Não por acaso, florescem as universidades privadas. De um lado, o sucateamento das universidades públicas e, de outro, "que é um outro lado da mesma medalha, a enorme expansão das universidades privadas, que se transformaram hoje, ao lado dos hospitais e

4 Deleuze refere-se aqui à educação francesa que, em início da década de 90, já prenunciava a diferenciação de salários para os professores de uma mesma escola. Nas universidades federais brasileiras, isso foi colocado em funcionamento, desde o final dos anos 90, quando foi instituída a Gratificação de Estímulo à Docência (GED). Esta prevê que, de acordo com a produtividade anual do professor, este terá um acréscimo ou não ao seu salário.

$5 \mathrm{Na}$ USP, nos últimos sete anos, 782 professores se demitiram. A Unicamp "acusou a baixa de 170 nos últimos dois anos”. Na UFRJ, em 1996, 281 docentes deixaram a instituição. Na UFF, nos anos de 1995 a 1999, 415 professores se aposentaram. $\mathrm{Na} U \mathrm{UNB}$, de janeiro de 94 a novembro de 97, 253 professores saíram do quadro. In: "A Diáspora dos Cérebros" - Revista Veja - 10/12/97 e "Professores abandonam universidades públicas" in Jornal do Brasil - 13/02/98, p 9. Em agosto de 2003, dados do Ministério do Planejamento apontavam que a média das aposentadorias de servidores públicos federais alcançou 1.597 até julho. Ou seja, apenas no $1^{\circ}$ semestre de 2003, as aposentadorias "superaram o total dos que deixaram a atividade 
das igrejas nos três melhores negócios do Brasil" (OLIVEIRA, 2002:36).

Tal quadro - sucintamente apresentado - aponta para uma competente produção: existiria uma tensão e, mesmo, oposição entre ciência (representada pelas áreas tecnológicas) e política (representada pelas "humanidades").

Diante da "objetividade", "racionalidade", "cientificidade" e "previsibilidade” presentes nas áreas das ciências exatas e biológicas teríamos em oposição a subjetividade, a pouca racionalidade e cientificidade e nenhuma previsibilidade por parte das ciências humanas.

Entretanto, cabe perguntar: quem determina e como são determinados os temas que deverão ser pesquisados pela academia? $\mathrm{O}$ que é legítimo de ser pesquisado? Como se produz essa legitimidade? (NOBRE, op. cit).

Ou seja, como nos aponta Silva (op. cit: 6):

Quem define as possiveis aplicaçôes do conhecimento à realidade, à sociedade? Quem define as necessidades dos lugares e momentos em que o conhecimento é produzido? Quem define a tal demanda social que o conhecimento e a universidade deveriam atender? (...) tais definiçôes resultam fundamentalmente da ação dos donos do poder instituído, dos donos do mundo político, do mundo econômico, do

em 2002. (...) As universidades e escolas técnicas são um dos maiores focos (...) Levantamento realizado pela Associação Nacional dos Dirigentes das Instituiçōes Federais de Ensino Superior (ANDIFES) informa que, até início de junho de 2003, 2.000 professores e técnicos administrativos se aposentaram”. In "Aposentadorias deste ano já ultrapassam as de 2002" - Folha de São Paulo - 28/08/2003, pa - 6. Em entrevista, o sociólogo Octávio Ianni, ao se referir ao momento em que essas aposentadorias estão se dando, quando da votação da Reforma da Previdência pelo governo Lula, afirma que "um governo que vem a partir de movimentos sociais está se dedicando muito apressadamente a satanizar a atividade intelectual na universidade pública. Portanto, está contribuindo para favorecer a privatização e o economicismo no primeiro, segundo e terceiro graus, que é um item do ideário de Washington, ou mais concretamente uma exigência do Banco Mundial". In: "Governo 'sataniza' funcionalismo para aprovar reformas, diz Ianni”" in Jornal da Unicamp, julho de 2003, no 220, p7. 
Coimbra, C. M.

"Tensão ou oposição entre ciência e política na pós-graduação? um falso problema?"

mundo da informação e outros winners, decision-makers e shitmakers em geral; os últimos homens que dirigem e são dirigidos por essa terrivel máquina social que resulta da fusão do Estado e do grande capital: o capitalismo moderno, agora também global.

Em minha vida acadêmica, tenho tido algumas experiências que apontam claramente nesse sentido.

Se, de um modo geral, dentro dos ventos neoliberais, as agências de governo em nosso pais - mediante processos bastante perversos aumentam sobremaneira as exigências quanto à capacitação de docentes de 'nivel superior' e, paradoxalmente, diminuem as condiçôes para tal, tornando-as cada vez mais restritivas e desistimulatórias, o que dizer de pesquisas que fogem ao instituido no âmbito acadêmico? O que dizer de pesquisas que propóem pensar o político, quando a área do profissional é a Psicologia? (COIMBRA, 2000: 254)

Em junho de 1997, quando de minha solicitação à CAPES de uma bolsa para pós-doutorado, no sentido de pesquisar a articulação que vem sendo produzida entre pobreza e periculosidade em nosso país, o parecer negando o pedido dizia o seguinte, dentre outras coisas:

As questôes levantadas (...) quase todas pertinentes à questão dos direitos humanos (...) em muitos momentos assumem um aspecto exclusivamente de denúncia, de panfletagem. Por mais que se possa concordar com o teor das denúncias e reconhecer e admirar o valor da militância da candidata (...) um projeto não pode ser formulado sem uma certa especificação de objetivos $e$ metodologia.(grifos meus)

Dentro da metodologia então apresentada, à época, para aquele projeto de pós-doutorado, seguíamos, dentro do referencial da análise institucional francesa, a chamada pesquisa - intervenção, onde pesquisador e pesquisado, sujeito e objeto do conhecimento 
se constituem no próprio processo da pesquisa. Não aceitamos - e isto era enfatizado no projeto - um a priori e um a posteriori: um objeto como algo a ser apreendido, como um a priori a ser conhecido e analisado a posteriori, como uma verdade a ser encontrada.

Foi em cima de tais questôes, que um outro parecer, o da FAPESP, respondendo a uma outra solicitação minha de bolsa de pós-doutorado, baseou-se para também negar o pedido. De forma mais sofisticada, "científica e objetiva" que o parecer da CAPES, o da FAPESP, de agosto de 1997, argumentava que a metodologia era "obscura, confundindo método com técnicas".

Estes exemplos, como dezenas de outros que ocorrem cotidianamente, utilizando os argumentos da incompetência e da pesquisa pouco qualificada podem ser considerados como situaçóes analisadoras ${ }^{6}$ que põem a nu a pseudo-objetividade do "tecnicismo cientificista" e que apontam a quem e a que, em realidade, essas pesquisas e esses pesquisadores de "primeira classe", que têm uma reconhecida "cidadania acadêmica", têm servido.

Não por acaso, em especial nas áreas tecnológicas, a política de privatização das universidades brasileiras, "resultante dos acordos entre o Ministério da Educação e o Banco Mundial, ganha proporções cada vez maiores (...)” (PAGANI, 2002:41).

Pressionadas pela insuficiência de recursos, as universidades federais, em especial suas áreas tecnológicas, incorporam esses paradigmas de produtivismo como normas indiscutíveis.

As universidades brasileiras abrem assim seus campi para a iniciativa privada por meio de convênios formalizados com as empresas (...). Não obstante isso, vão, elas próprias assumindo o caráter de empresa privada, com a criação de fundações, por exemplo (PAGANI, op. cit.).

6 Por analisador entendemos, dentro das contribuições trazidas pela analise institucional francesa, acontecimentos que, por si só, colocam em análise as instituições, as relações percebidas como naturais e até mesmo necessárias. Tais acontecimentos falam por si, produzem sua própria análise. 
Coimbra, C. M.

"Tensão ou oposição entre ciência e política na pós-graduação? um falso problema?"

Em especial, nas áreas das ciências tecnológicas, encontramos, praticamente em todas as universidades públicas brasileiras, fundações de direito privado. De um modo geral, as humanas e sociais "como não têm fundação, como não vendem seus serviços no mercado, estão desprovidas de quase tudo" (OLIVEIRA, op. cit.).

Da mesma forma, naquelas mesmas áreas tecnológicas, cursos de extensão e especialização vêm sendo velozmente criados tendo como principais parcerias grandes empresas.

Seis anos após ter sido criada, a Escola de Extensão da Unicamp (Extecamp) dispunha, em 1995, de 451 propostas de cursos em seu catálogo. Quatro anos depois, em 1999, a oferta somava 1.095 cursos. Em 2002, o catálogo da escola oferece nada menos do que 1.738 cursos (REVISTA ADUNICAMP, 2002:43).

Oliveira (op.cit:40) chama a atenção para o fato de que nos programas dos mais diferentes partidos políticos, em especial nos que se colocam como de esquerda, não se encontra nenhuma menção ao aumento de verbas para as universidades públicas brasileiras.

Isso mostra o lugar que os partidos politicos, (...) reservam à universidade (...) Porque a Universidade pública suscita imediatamente - e ninguém pode fugir a isso - aumento dos gastos do Estado. E um gasto do Estado que está comprimido pela obrigação de apresentar um superávit primário de 3,57\% ao FMI. Desse modo, não tem ninguém que se meta a dizer escancaradamente "vou aumentar o gasto estatal com educação superior". E é isso que é preciso (...) Dai a grande vitória neo-liberal (...). Faz-se uma certa referência ao gasto que diretamente incide sobre as condiçōes de miséria, de pobreza do país, e não se fala de educação superior pública e laica, que é certamente um dos lugares onde gastos públicos podem ser mais eficientes para a democratização e para a aniquilação da pobreza. Eu não vejo isso nos programas políticos, infelizmente.

Diante do atual quadro político-econômico brasileiro o deputado federal Chico Alencar (2003) indaga se: 
Psicologia \& Sociedade; 16 (1): 86-97; Número Especial 2004

Os investimentos em educação, saúde, habitação e cultura continuarão restritos no Orçamento de 2004, substituindo-se as politicas sociais universais pelas açôes focadas, pontuais e de cunho assistencialista? (O GLOBO, 22/08/2003)

Diante desse quadro não há motivos, portanto, para estranhar a ausência de determinados temas mesmo nos cursos de graduação ligados às ciências humanas e sociais, nas suas pesquisas e extensões. Em especial na Psicologia, temas que se colocam como políticos têm sido classificados como não científicos, não acadêmicos; é como se fizessem parte de um outro território: o da militância. Daí, a sua quase total ausência nas pesquisas, extensões e nas pósgraduações.

Entretanto, há linhas de fuga, há singularidades atrevidamente sendo construídas; há, enfim, vida pulsando nos mais diferentes territórios, por mais estigmatizados, desqualificados ou mesmo negados. Há, apesar desses extertores que vivemos, rupturas sendo produzidas por mais microscópicas e invisíveis que sejam.

$\mathrm{Na}$ Psicologia estamos percorrendo alguns caminhos. Procuramos incluir a política como uma necessária dimensão de nossa prática. Pretendemos entender o homem, seus pensamentos, percepções, sentimentos e ações como produções histórico-sociais, assim como analisar os efeitos de nossas práticas enquanto profissionais-cidadãos produzidos e produtores que somos. Potencializar a vida e nos aliarmos a ela, em especial aos movimentos que se espalham pelo mundo, tem sido um dos nossos desafios.

Ou seja, a luta vai mudando de patamar, de estratégias, criando novos dispositivos.

Seatle, Quebec e Porto Alegre nos ensinam que os poderes têm cada vez mais dificuldade de se reunirem em qualquer lugar do planeta (...) A luta não terminou. Para além das ideologias, para além até mesmo das questôes de classe, agora o conflito concerne à própria vida, isto é à sua defesa ou à sua apropriação. (LAYMERT, 2002:28) 
Coimbra, C. M.

"Tensão ou oposição entre ciência e política na pós-graduação? um falso problema?"

\section{REFERENNCIAS}

CAPES. Resposta à solicitação de bolsa. Brasília, junho de 1997.

CHOMSKY, N. La liberalización financieira ha creado un senado virtual que gobierna el mundo. In: Rebelión: Notícia. Washington, fevereiro/1998.

COGGIOLA, O. Ciências Humanas: o que são, para que servem In Revista ADUNICAMP, ano 4, no 1, novembro de 2002, 07-18.

COIMBRA, C. M B. Operação Rio: o mito das classes perigosas. Rio de Janeiro: Oficina do Autor/Intertexto, 2001.

DELEUZE, G. Conversaçôes. Rio de Janeiro: Editora 34, 1992.

FAPESP. Resposta à solicitação de bolsa. São Paulo, agosto de 1997.

Folha de São Paulo. 28/08/2003.

JORNAL DO BRASIL. 13/02/1998.

JORNAL DA UNICAMP. julho de 2003, no 220.

LAYMERT, G. dos S. Perspectivas que a revolução micro-eletrônica e a internet abrem à luta pelo socialismo. In: Revista ADUNICAMP, ano 4, no. 1 , novembro de 2002, 19-28

NOBRE, M. As Ciências Humanas na encruzilhada do socialdesenvolvimentismo. In: Revista ADUNICAMP, ano 4, no 1 , dezembro de 2002, 29-34.

O GLOBO - 23/08/2003.

OLIVEIRA, F. de. As humanidades em um contexto de crise da universalidade In Revista ADUNICAMP, ano 4, no 1 , novembro de 2002, 35-40.

PAGANI, M. C. Oferta de cursos pagos cresce na Unicamp: universalização do conhecimento ou mercantilização do ensino? In: Revista ADUNICAMP, ano 4, $\mathrm{n}^{\circ} 1$, novembro de 2002, 41-42. 
REVISTA VEJA. 10/12/1997.

SEVCENKO, N. O Professor como corretor. In: Caderno Mais. Folha de São Paulo 04/06/2000.

SILVA, S. Um Ideal. In: Revista da ADUNICAMP, ano 4, no 1 , novembro de 2002, 05-06.

Cecilia Ma Coimbra é Psicóloga, Professora Adjunta da UFF, Pós-doutora em Ciência Política pela USP. Fundadora e atual Vicepresidente do Grupo Tortura Nunca Mais/RJ.

$O$ endereço eletrônico da autora é: gtnm@alternex.com.br

Cecília Maria Coimbra

Tensão ou oposição entre ciência e política na pós-graduação? Um falso problema? Recebido: 8/11/2003

Aceite final: 3/5/2004 